\title{
Symbolic Interaction as Music: The Esthetic Constitution of Meaning, Self, and Society
}

\author{
Phillip Vannini \\ Royal Roads University \\ Dennis Waskul \\ Minnesota State University
}

\begin{abstract}
Analytical frameworks such as dramaturgy and narrative analysis are respectively grounded in metaphors of life as theater and life as a story. In related fashion, in this article the authors argue for the creation of another metaphor: life as music. Viewing selfhood and symbolic interaction as music sensitizes us to observe and understand an important but much too neglected dimension of social life: the esthetic. Drawing from the pragmatist philosophy of John Dewey, the authors argue that the realm of the esthetic should not be confined to museums and art galleries, for the intentional perception of beauty constitutes the very foundation of individuals' embodied experiences of their lifeworlds. From within our metaphor of life as music we conceptualize beauty as the diverse rhythms, melodies, and harmonies contributing to the constitution of both subjectivity and intersubjectivity.
\end{abstract}

Although generally neglected by sociological theory and research, esthetics is undeniably important in individual and collective life. In this article we argue for a revitalization of symbolic interactionist and sociological concern with esthetics while also proposing a metaphor of symbolic interaction as music. Esthetic value is omnipresent in life, the natural environment (Dewey 1925), the arts (Becker 1982) and sciences (Dewey [1934] 1959), household possessions (Csikszentmihalyi and Halton 1981), and work and occupations (Fine 1996). However, for the sake of developing a consistent and cohesive metaphor, we will limit our discussion to the value of esthetics in music, without making any distinction between classical and popular music. Widely accepted dramaturgical and narrative metaphors structure understandings of numerous aspects of symbolic interaction, yet neither directly concerns the important role of esthetics in the constitution of meaning, interaction, self, and society.

Direct all correspondence to Phillip Vannini, School of Communication and Culture, Royal Roads University, 2005 Sooke Road, Victoria BC V9B 5Y2, Canada; e-mail: vannini@lycos.com.

Symbolic Interaction, Vol. 29, Issue 1, pp. 5-18, ISSN 0195-6086, electronic ISSN 1533-8665. (c) 2006 by the Society for the Study of Symbolic Interaction. All rights reserved. Please direct all requests for permission to photocopy or reproduce article content through the University of California Press's Rights and Permissions website, at http://www.ucpress.edu/journals/rights.htm. 
By emphasizing esthetics, a musical metaphor based on sound as iconic may prove useful and strategic for a wide variety of conceptualizations and analyses. Our premise is that, by discerning how musical esthetics emerges out of music-making, we should be able to craft understandings of how esthetic dynamics inform the constitution of meaning (i.e., semiosis) in contexts well beyond music proper. We begin by discussing music as a metaphor for symbolic interaction and reflecting on the importance of esthetics. We then examine how music sensitizes uniquely esthetic and somatic understandings of the constitution of meaning, self, and society.

\section{MUSIC AS METAPHOR}

Music is many things: organized sound, a social construction, a perception, and an external fact that is produced and consumed. History, culture, and society highly influence music. Sounds defined as music are produced, perceived, and processed within and by means of a broad array of historical, cultural, and social resourcesboth material and symbolic. Definitions of music are predictably varied. However, for our purposes we propose an approach whereby music is characterized by qualities perceived as such. It is certain qualities of sound that characterize music, key among them are melody, harmony, rhythm, tone color, and form. Harmony refers to the combination of two or more simultaneous sounds in a manner that is deemed esthetically pleasing. Rhythm refers to the organized movement, duration, variation, and pattern of sound. Tone color (or timbre) refers to the unique quality or character of sound. Melody refers to a succession of sounds heard as a unit. Form refers to the structure of a musical product or, in other words, to the relation between parts and whole.

We propose that these same qualities structure a musical metaphor for understanding the nuances of interactions in everyday life. In short, symbolic interaction is musical. Symbolic interaction is harmonic in the sense that relationships with others yield more than instrumental value. Interactions with others are esthetic, and we routinely gauge relations on the basis of such gratifications. Symbolic interaction is rhythmic in the sense that interactions with others and self are characterized and understood in terms of organized variation and patterns of duration. Symbolic interaction has tone color in the sense that each interaction (and each moment of interaction) has its own unique quality or character, no matter how subtle that uniqueness might be. Symbolic interaction has form in the sense that it occurs in a context that structures the nature of what is done, the means by which it is achieved, and how it is perceived. Symbolic interaction has melody in the sense that relationships with others and self are experienced as continuous units with variable esthetic value from unit to unit rather than as disassociated fragments. And finally, in a sense, symbolic interaction is like a musical composition insofar as it is an unfolding process experienced as a complete phenomenon in its wholeness, as well as in its parts. The presence and variation of these qualities are what uniquely structures and defines both music and the experience of everyday life. 
These general applications aside, a significant part of the utility in conceiving of symbolic interaction as music is the distinctive quality of music as an irreducible system of signification. Music is semiotically unique, a fact that continues to escape the attention of much sociological research. Music's semantic properties are material, yet also irreducible to linguistic language, and therefore represent a unique esthetic condition that potentially informs the structuring of interaction, self, society, and human expression. The uniquely iconic nature of music holds considerable promise for a symbolic interaction as music metaphor; it directs attention not only to esthetic dimensions of human social life but also to nonsymbolic processes that are seldom included in interactionist analysis.

We do not intend to reduce symbolic interaction to musicology, or even society to music-our use of metaphor is purely strategic and contingent. As Lakoff and Johnson (1980:145) have explained: "Many of our activities (arguing, solving problems, budgeting time, etc.) are metaphorical in nature. The metaphorical concepts that characterize those activities structure our present reality." Metaphors widely applied by symbolic interactionists and other interpretive sociologists alike are, among others, that of life as theater (Goffman 1959) and life as narrative (e.g., Holstein and Gubrium 2000). Such metaphors, by employing specific dynamics and concepts, orient our understanding, sanction actions, justify inferences, and help us set goals (Lakoff and Johnson 1980). Generally, dramaturgy sensitizes communicative, performative, and moral dimensions of everyday life. Narrative analyses highlight the collective logical properties of events, demonstrating how individuals and groups turn disordered happenings into logically, emotionally, and consequentially ordered chains of temporal events significant to individual biography and collective memory. Neither of those two metaphors, nor the one espoused here, entirely reduces complex social phenomena to circumscribed symbolic arenas. Metaphors simply work as stratagems soliciting particular forms of thought and action.

New metaphors, like the one advanced here, "have the power to create a new reality" by bringing about new meaning, highlighting certain features of thought and action, and suppressing others (Lakoff and Johnson 1980:145). Indeed, we propose "symbolic interaction as music" out of the need to sensitize ourselves to the importance of esthetics, as explained, but also to amend symbolic interactionism's tendency to view meaning as exclusively symbolic - as the very expression "symbolic interactionism" suggests (Halton 1986:39). By visualizing symbolic interaction as music, we hope to direct attention to components of meaning, as expressed and experienced in music, that are esthetic in a manner that is not entirely captured if limited to the purely symbolic. As symbolic interactionists-Halton (1986:39) reminds us-we have indeed neglected to "include the iconic or qualitative signs as contributing in their own right to the communicative process." Our metaphor, we hope, can therefore sensitize us to the iconic dimensions of meaning.

As some sociologists have noted (e.g., Brown 1977; Fine 1996; Nisbet 1976), the difficulty of studying esthetics from a sociological perspective is both ontological and epistemological. Most commonly in sociology, esthetics is reduced to linguistic 
discourse and practice, thus losing immediate, somatic, and esthetic qualitieswhich is, incidentally, the very reason esthetics is of any significance whatsoever. Consequently, we suggest that the difficulty of studying esthetics sociologically resides precisely in generating knowledge about beauty through conceptual, analytical, and representational schemes that have nothing to do with the nature of beauty itself. Our intent is to avoid this problem by revealing the connection between esthetics and social effects and by treating esthetics as an irreducible form of human expression and meaning. In short, we intend to develop a metaphor of symbolic interaction as music, avoid the reduction of esthetics to discourse, discursive practice, and material substance, and do so by highlighting how esthetic value in music resides not in language but instead in a relationship between somatic experience, rhythm, harmony, melody, tone color, and form. ${ }^{1}$

\section{MEANING AS MUSIC}

Blumer's (1969:2) three premises of symbolic interactionism are a helpful starting point for structuring a musical metaphor: meaning is derived from, or arises out of, processes of musical interaction that one has with others; meaning is handled in, and modified through, a poietic and esthetic process used by people in dealing with things encountered; human beings act toward things on the basis of the musical forms, tone colors, rhythms, melodies, and harmonies that things have for them. Let us begin by examining in some depth musical meaning. We will then show how musical meaning allows for a clearer conception of qualitative esthetic immediacy for all forms of meaning.

Musical meaning is not always symbolic. Symbolic meanings are typical of language-language being only one system of signification among many others. Simply stated, a symbol is an arbitrary substitute for something else; a symbol is what allows us to indicate something apart from the actual thing to which the symbol refers. But what do the components of music refer to, if anything? What does a sound refer to if not, apparently, itself? Properly speaking, then, music is - at least in most circumstances-iconic rather than symbolic (see Nattiez 1990). This division originates in the semiotics of Charles Sanders Peirce (1931), who identified three types of signs: the indexical, the iconic, and the symbolic. Simply put, the symbolic is "a mode in which the signifier does not resemble the signified but which is fundamentally arbitrary or purely conventional—so that the relationship must be learnt," as in language and words. The indexical is "a mode in which the signifier is not arbitrary but is directly connected in some way (physically or causally) to the signified," as in natural phenomena like smoke being indexical of fire. The iconic, however, is "a mode in which the signifier is perceived as resembling or imitating the signified (recognizably looking, sounding, feeling, tasting or smelling like it)" (Chandler 2002).

It is generally agreed that, in most contexts, music is iconic. What has never been properly understood about music as a system of signification is the esthetic role of sound and, in particular, how properties of sound such as tone color, form, harmony, 
rhythm, and melody are recognized as such. This problem in understanding significance resides in the seemingly abstract or non-denotative property of music. Music is non-denotative in the following sense:

The sounds of music do not obviously refer outside themselves to the world of objects, events and linguistically encodable ideas. In terms of the way in which symbols are commonly understood to have meaning, this "abstract" aspect of music emerges either as having "no meaning," or as having a meaning that is quite distinct and apart from all other forms of meaning. ... This difficulty has served to perpetuate and entrench within musicology the assumption that, if music can be accepted as in some way having meaning, then this meaning must be intrinsic or immanent to music's sounds. (Sheperd and Wicke 1997:10-11)

Thus, understanding meaning as music reveals the first apparent problem: the difficulty in explaining nonsymbolic meaning. Traditionally, whereas many musicologists have essentialized the meaning of sounds by treating meaning as immanent to music, sociologists and cultural theorists have solved this problem by translating the iconic realm of musical meaning into the symbolic realm of language and practice. Constituting the meaning of music in discourse is typical, for example, of scholars like Lawrence Grossberg (1993:41), who have explicitly argued that we should "locate musical practices in the context of a complex (and always specific) set of relations with other cultural and social practices," thus effectively favoring the description and analysis of music "as a cultural rather than a musical formation." The problem with this approach is that by treating iconic sound as a form of symbolic sound - and by treating the semiotic system of music as if it were linguistic — we fail to consider "that characteristics of music's signifying practices specific to itself constitute an important and inescapable part of social and cultural processes" (Sheperd and Wicke 1997:33).

The view that language and music share the same properties originates from the notion that both words and musical tones are nothing but sounds and systems of sounds to which meaning is affixed. As systems of signification, both linguistic sounds and musical sounds are assigned meanings by people in social interaction within circumscribed social, political, and cultural contexts-or at least this is what, as constructionists, we believe. As useful as this approach may be, it misses an important dimension of musical meaning. Even though music and language are culturally constituted forms of human expression that give rise to meaning and affect, they do so in ways that are not always the same.

Following Peirce, we define musical sound as a sign. Granger (1968:114) presents Peirce's triadic model of the sign in the following accessible form: representamen is "a thing which is connected in a certain way to a second sign, its 'object,' in such a way that it brings a third sign, its 'interpretant,' into a relationship with this same 'object,' and this in such a way that it brings a fourth sign into a relationship with the same 'object,' and so on ad infinitum." Understanding a sign in this manner allows us to locate the genesis of meaning within the reflexive relation among sound, its perception, and that for which the sound stands. For the French Peircean musicologist Jean-Jacques Nattiez (1990), three dimensions of musical meaning must be taken 
into account if the meaning(s) of music is (are) to be understood: the process of music generation, the configuration of sounds to which such process gives rise, and the process of musical interpretation. In Nattiez's words,

Three dimensions of this symbolic phenomenon thus emerge: (a) the poietic dimension: even when it is empty of all intended meaning ... the symbolic form results from a process of creation that may be described or reconstituted; (b) the esthetic dimension: "receivers," when confronted by a symbolic form, assign one or many meanings to the form; the term "receiver" is, however, a bit misleading. Clearly ... we do not "receive" a "message's" meaning (since the producer intended none) but rather construct meaning, in the course of an active perceptual process; (c) the trace: the symbolic form is embodied physically and materially in the form of a trace accessible to the five senses. We employ the word trace because the poietic process cannot immediately be read within its lineaments, since the esthetic process (if it is in part determined by the trace) is heavily dependent upon the lived experience of the "receiver." (1990:11-12)

Nattiez's conceptualization of musical meaning is useful because, by treating musical meaning as a process, it diverts our attention away from the structure of sound as the locus of musical meaning. More importantly, by viewing a musical work as a set of social configurations "constituted by the procedures that have engendered it (acts of composition), and the procedures to which it gives rise: acts of interpretation and perception" (1990:ix), Nattiez brings to the forefront the importance of the esthetic affect to meaning.

It is important to clarify what is intended by esthetic and poietic within the context of music. Esthetic refers to the process of "enjoying, contemplating, or reading" (Nattiez 1990:12) a musical trace. Poietic, on the other hand, refers to the process of creation of a text/performance (also known as trace). More precisely, for Gilson (1963) Nattiez's inspiration muse-the poietic is divided into three elements: "deliberations on what must be done to produce the object, operations upon external materials," and "the production of the work" (Nattiez 1990:12-13). Because both the poietic and the esthetic phenomena are processes through which sound takes on affective meaning, Nattiez's perspective-based in part on the untranslated French writings of Jean Molino-seems quite intriguing for symbolic interactionists interested in rediscovering the esthetic dimensions of meaning.

Nattiez's framework provides deeper insights into the social and musical constitution of musical meaning - and, by extension, symbolic meaning — but it also allows us to resolve the conundrum of the alleged asemantic or non-denotative properties of music. As stated earlier, music is non-denotative or asemantic because, in most contexts of use, sounds refer to themselves and not to external material referents. Such a conclusion is only warranted, however, from a structural perspective. A pragmatic understanding of musical meaning, based on Peircean semiotics, leads us instead to believe that "what we ordinarily call denotation designates a constellation of interpretants that are common to the poietic and the esthetic. As long as an interpretant is situated, in isolation, on either the poietic or the esthetic side, then we have entered into the sphere of connotation" (Nattiez 1990:24). With Peirce and Nattiez we 
have the possibility of understanding musical meaning as a unique mode of signification, without translating music into the symbolic realm of language and also without excluding the social dimensions of musical meaning. All that is needed, at least for now, is a clearer vision of the constellation of interpretants that arise from the connection between the poietic and the esthetic. Following Francès (1958) and Nattiez (1990:103), four types of interpretants are associated with music: (1) "normative judgments (personal evaluations, judgments of taste)"; (2) “objective judgments, or judgments of a technical nature"; (3) affirmations related to the psychological effect experienced by the subject; and (4) "judgments about meaning, in which the subject attributes to the stimulus a content referring to an extramusical referent." The last interpretant is further divided into (1) individual referents (as in the relation between music and some aspect of personal history and identity); (2) concrete meanings (as in a specific aspect of nature or phenomenon in the outside world); and (3) abstract meanings (related to generalized representations and states of being like order, disorder, happiness, sadness, etc.). Understanding the complexity and diversity of this system of interpretants allows us to surpass overly simplistic conceptualizations of "taste" (e.g., Bourdieu 1984).

Musical denotation, for Nattiez, is therefore not about the structural relation between sound and an ideal referent but instead about the social and sonorous relation between the moment(s) and agent(s) of poiesis and the moment(s) and agent(s) of esthesis. Both the poietic and the esthetic process equally inform normative judgments, psychological effect (and somatic affect, as we argue), concrete meanings, and abstract meanings. With what we now know we can conclude that musical meaning — whether at the denotative or connotative level-emerges out of a process of musical interaction that one has with others and that meaning is handled in, and modified through, a poietic and esthetic process; but we cannot yet suggest that - as the logical coherence of our metaphor demands - symbolic meaning emerges out of a similar process. To understand what musical meaning shares with symbolic meaning, let us reflect on the similarities and differences between the two.

\section{MEANING AS ESTHETICS}

As suggested, conceiving of symbolic interaction as music has great potential to sensitize esthetic properties of meaning and interaction. Esthetics tend to escape interpretive sociologists' analysis because, in part, understanding esthetics relies on understanding qualitative immediacy — a much neglected dimension of meaning. Halton (1986) reminded us that concerns with the esthetic and with the qualitative immediacy of experience were common among some of the founders of American pragmatism, namely Peirce and Dewey. Whereas Gary Alan Fine (e.g., 1996) and Howard S. Becker (e.g., 1982), among others, have contributed to our understanding of esthetics, Eugene Halton (Csikszentmihalyi and Halton 1981; Halton 1986) is the only symbolic interactionist who has paid explicit attention to qualitative immediacy-the dimension of esthetics with which we are primarily concerned here. 
To understand qualitative immediacy, we must first recollect that Peirce (1931, vol. 1) distinguished three kinds of phenomena: firstness, or immediate quality; secondness, or the actuality of existence; and thirdness, generally understood as representational knowledge or thought. With these distinctions, Peirce argued against immediate knowledge obtained through introspection or intuition and in favor of immediate consciousness through feeling, which he defines as quality or firstness: "an instance of that sort of element of consciousness which is all that it is positively, in itself, regardless of anything else" (1931, vol. 1:306). Qualitative immediacy is therefore not a matter of reflexive emotion (because of the self-knowledge that reflexive emotionality entails) but instead a matter of "pure" feeling-pure in the sense that it is a first qua first experience:

The poetic mood approaches the state in which the present appears as it is present. The present is just what it is regardless of the absent, regardless of past and future. Imagine, if you please, a consciousness in which there is no comparison, no relation, no recognized multiplicity (since parts would be other than the whole), no change, no imagination of any modification of what is positively there, no reflection-nothing but a simple positive character. Such a consciousness might be just an odour, say a smell of attar; or it might be the hearing of a piercing eternal whistle. In short, any simple and positive quality of feeling would be something which our description fits that it is such as it is quite regardless of anything else. The quality of feeling is the true psychical representative of the first category of the immediate as it is in its immediacy, of the present in its direct presentness. (Peirce 1931, vol. 5:44)

By arguing for firstness and qualitative immediacy, Peirce is not suggesting that knowledge of the present is (or can be) un-mediated. Instead Peirce suggests that, at the level of qualitative immediacy, we simply have no knowledge; we have nothing but feeling (see Halton 1986:26). In relation to the esthetics of music, the point taken from Peirce is that iconic signs "are signs of qualitative immediacy, and as such signify the qualitative possibility or pervasive quality of the communicative act" (Halton 1986:29). Hence, attentiveness to the qualitative immediacy of iconic signs like music sensitizes to the understanding of esthetic experience.

Despite writing little about esthetics per se, Peirce's idea of truth and goodness are rooted in esthetic value. On esthetics Peirce remarked, "it seems to me that while in esthetic enjoyment we attend to the totality of feeling-and especially to the total resultant Quality of Feeling presented in the work of art we are contemplating-yet it is a sort of intellectual sympathy, a sense that here is a Feeling that one can comprehend, a reasonable Feeling" (1931, vol. 5:113). We can understand what Peirce later referred to as the category of quality of feeling through Halton (1986:29), who explains that "by 'Category of Quality of Feeling' Peirce means that the esthetic experience essentially involves a sign of Firstness, or iconicity, in his simplest threefold division of signs. . . . The esthetic element of experience, as Dewey would later elaborate, involves the communication of qualitative signs, whose meaning is the quality conveyed regardless of what conventions may be used to express that quality." It is important to emphasize that, although quality exists 
regardless of conventions, an act possesses quality only in relation to a constellation of interpretants and, therefore, to the possibility of future interpretation. Quality is therefore not an essence but an irreducible "mere possibility" (Peirce 1931, vol. 1:310) quintessential to the uniqueness and creative power of human action and experience. Through Peirce we thus have a key for unlocking the mystery of musical meaning and meaning in general. Leading us from this point forward is the pragmatist philosophy of John Dewey, whose conceptualization of experience as art and art as experience is at the core of our metaphor of symbolic interaction as music.

Dewey's theory of qualitative immediacy is contained in Experience and Nature (1925) and Art as Experience ([1934] 1959). Dewey (1925) describes how the experience of thinking has its own quality distinct from esthetic experience because, whereas the experience of thinking is primarily symbolic, the esthetic-to use Peirce's terminology-is iconic (see Halton 1986:31). This is not to suggest that Dewey supported the dichotomy between intellectual thought and esthetic perception; on the contrary, Dewey's "deconstruction" of all such dichotomies is precisely what made the later Art as Experience an authentic treasure of sociological insights. The difference between intellectual and esthetic experience, instead, lies in the following:

The material of fine arts consists of qualities; that of experience having intellectual conclusion are signs or symbols having no intrinsic quality of their own, but standing for things that may in another experience be qualitatively experienced.... Nevertheless, the experience itself [of thinking] has a satisfyingly emotional quality [as well] because it possesses internal integration and fulfillment reached through ordered and organized movement. This artistic structure may be immediately felt. In so far, it is esthetic ... no intellectual activity is an integral event [is an experience], unless it is rounded out with this quality. Without it thinking is inconclusive. (Dewey [1934] 1959:38)

Esthetic imagination and the power of the esthetic value in constituting affective meaning are for Dewey, and later for Mead-whose esthetic component of consummation Dewey influenced (Mead 1926:384)—what makes possible the regeneration of the human spirit and the "language of delight into which men can translate the meaning of their own existence" (Mead 1938:457). The esthetic is thus the condition for the unity of all experience: "No experience of whatever sort is a unity unless it has esthetic quality" (Dewey [1934] 1959:40).

Dewey's understanding of meaning and experience and his attempt to recover the continuity of esthetic experience throughout all life processes are enormously useful here, because they allow us to break free of the ideologies that compartmentalize the fine arts within themselves while separating them from everyday experience. As a consequence, they allow us to suggest that, despite differences, mundane experience can be understood through the lens of music. For Dewey, art and beauty are not exclusive subject matter for museums, galleries, theaters, and concert halls but instead the pivotal elements of a system of thought, known as the esthetics of continuity (Shusterman 1992), that bridges the oppositions of high and popular arts, the emotional and the cognitive, the esthetic and the intellectual, the mind and the 
body, form and substance, the self and its lifeworld, and the artist and its audience, among many others. The esthetic potentially informs all kinds of experiences and meanings by involving creatures with their unity and variety, by binding the parts together with the whole of the experience of quality, by rendering experience active, dynamic, and rhythmic, by providing resolution to struggle and overcoming resistance, by shaping "satisfying form, where means and ends, subject and object, doing and underdoing, are integrated into a unity" (Shusterman 1992:56), and especially by pointing us, as has been said, to the directly fulfilling qualities of immediate experience. In sum, for Dewey, despite differences in degree from actual case to actual case, experience is art, and meaning is esthetic.

The only thing standing in the way of the esthetic experience for Dewey is the humdrum character of much of mundane existence. Therefore, following Dewey ([1934] 1959), we should be prepared to deal with two types of communicative acts: recognition, in which meaning depends on a previous habit of interpretation, and perception, in which there is novel appreciation, evaluation, understanding, and feeling. Perception is the unique and spontaneous creative process through which esthetic affect is generated.

Dewey ([1934] 1959) details how meaning is in part constituted by instrumental value and in part by intrinsic value-without the necessity of an opposition between the two. By pointing out that meaning is esthetic, we can also understand that meaning is not only a form of will to power but also (and perhaps in the same sense) a form of will to esthetics that satisfies human beings in a different manner by allowing us to achieve a greater variety of goals and by sensitizing us to the intrinsic utility of a sensible and sensitive mode of living.

Having conceptualized the firstness of iconicity and the qualitative immediacy of esthetic perception, our earlier use of Nattiez can now be extended to conceptualize semiosis as the constitution of meaning as beauty. Dewey, much like Nattiez (1990), distinguished between art as making or doing and esthetic experience as consumptiona view consistent with the poietic and esthetic dimensions of musical semiosis. We are thus consistent in suggesting that both the production and the perception of musical meaning and all meaning should be understood as similar, for in both cases the will to meaning is the will to esthetic creation as "a realization of meaning through interaction with the inherent qualities of the object" (Csikszentmihalyi and Halton 1981: 179). The only problem at this point in the development of our metaphor is the following: if musical meaning in its iconicity is so different from symbolic meaning, how can we suggest that musical semiosis shows us anything of value in understanding the constitution of symbolic meaning? The answer comes from Dewey himself and this earlier cited passage: "No experience of whatever sort is a unity unless it has esthetic quality" (Dewey [1934] 1959:40). The difference between the perception of iconic qualities and the perception of symbolic meaning is a matter of experience and the degree of reflexivity. Furthermore, though so far we have focused on the differences between the two, we should also reflect on the similarities. Examining both the differences and the similarities between music and meaning is necessary to show how 
treating symbolic interaction as musical interaction and symbolic meaning as musical meaning is both advantageous (because there is diversity between the two) and feasible (because there is similarity). The similarity, as we explain in the following section, resides in the fact that-following the first Blumerian premise of symbolic interactionism and our reworking of it within our metaphor-human beings act toward things on the basis of the musical rhythms, melodies, tone colors, forms, and harmonies that interaction with the things provides. This link between the embodied self, music, and esthetics thus forms the origin of musical and symbolic meaning.

\section{MUSIC, ESTHETICS, AND THE SENSUAL BODY}

To say that music is iconic and qualitatively immediate is to implicate the somaticmusic is not only produced and perceived, it is experienced by the senses. Thus, to advance our metaphor of symbolic interaction as music, it is necessary to emphasize somatic experience- the sensual body "as the site through music for the mediation of social and symbolic processes"-and music's esthetic character as flowing "as much from its unique contribution to social processes as . . f from its capacity to symbolize them" (Sheperd and Wicke 1997:3). Indeed, the core similarity between musical (i.e., iconic) meaning and symbolic meaning is their origin in somatic naturalism. For Dewey ([1934] 1959), esthetics is rooted in the natural needs, physiological constitution, and activities of organisms — or, in other words, in "somatic naturalism" (Shusterman 1992:6). Because esthetics lies at the basis of all vital functions and therefore at the very point of the origin of life and interaction between living organisms, their environment, and other organisms, esthetics serves as the force sustaining the organization and "reorganization of energies, actions, and materials" (Shusterman 1992:6). Thus, even though musicbecause of its qualitative immediacy and iconicity-may sensitize us to the perception of beauty, the kind of accumulation, tension, release, anticipation, and fulfillment typical of music remain defining features of all kinds of experience.

By advocating a somatic esthetics and by rooting meaning in somatic experience with Dewey, we turn to a physiology of esthetics, or perhaps to an esthetics of physiology, that resonates in part with Nietzsche, Bataille, and Foucault, as well as with Merleau-Ponty's grounding focus on the lived body (see Shusterman 1992:9). From within the Deweyan understanding of esthetics, we can then treat music not as a conduit for the exchange of information and ideas - as do models that reduce musical meaning to symbolic meaning - but instead as the rhythmic succession of "muscular chaos" (Washabaugh 1996:91) and harmony. Meaning as music, therefore, becomes a sensorial phenomenon through which the textures of physical experience are refracted onto the textures of sound, through both the poietic and esthetic processes. Symbolic interaction turns into an iconic interaction (although not exclusively so); not a conversation of gestures but rather a communicative possibility of fusion between otherwise separate somatic experiences.

Grounding esthetic meaning into the sensual body is not a way of embracing subjectivism. Meaning does not reside in isolated bodies but instead in the connection 
between living organisms and the iconic trace. But our metaphor of meaning as music goes even further. Following Dewey ([1934] 1959), we suggest that music is life, and life is musical. Viewing symbolic interaction as music entails viewing not only semiosis but also individual somatic existence and even group life as a musical experience. Losing musicality is a way (see Sacks 1990:60) of losing the grace, beauty, and sonorous continuity of life. "Having" musicality, following Dewey, or "feeling" the qualitative immediacy of musicality, following Peirce, is instead a common characteristic of normal existence. The musicality of existence is, however, more than a physiological condition. Musicality-at least within our metaphor-becomes an existential goal to which all aspire. Outside of metaphor, esthetic meaning becomes an existential goal of the somatic self.

The connection between music and the body-and between esthetic meaning and the somatic-resides, therefore, in the action music generates. The long-standing tenet of pragmatism that the meaning of things resides in the interpretation engendered and in the action directed toward them turns here into the realization that meaning resides in the embodied poietic and esthetic action directed toward music. Willis (1978) and DeNora's empirical findings on the function music plays in everyday life clearly corroborate the idea that "music is an active ingredient in the organization of self, the shifting of mood, energy level, conduct style, mode of attention and engagement with the world" (DeNora 2000:61). Music, therefore, hardly ever works as a stimulus causing an affective effect. Music $i$ s the resonance of individuals acting in concert with one another; the tone of music is the setting, its genre is the type of interaction, its tempo is the emotional energy of the participant(s) involved in social interaction, its poietic and esthetic constitution is the affective color of meaning and experience, and its rhythms, melodies, and harmonies are the corporeal desires, moods, and feelings of social agents involved. Symbolic interaction as music is then a practical, esthetic accomplishment, an expression of meaning as esthetic and esthetic as intersubjective, somatic affect.

Viewing symbolic interaction as music, therefore, allows us to capture not only the esthetic and social dimensions of meaning-making (meaning arising out of the interaction of social agents) as well as the semiotic and esthetic dimensions of meaning (meaning originating out of the conduct of people toward it), but also-following Blumer's (1969) first premise-how social agents act toward things on the basis of the musical tone colors, forms, rhythms, melodies, and harmonies that the things have for them. In fact, the music metaphor gives symbolic interaction an entirely new depth: the depth of tone color, form, rhythm, melody, and harmony.

Rhythm, form, tone color, melody, and harmony stand as the somatic dimensions of poietic and esthetic experience and meaning because, indeed, they do not originate as immanent properties of sound but instead as the somatic perception of musical traces or, in other words, as the product of poietic and esthetic perception. Viewing symbolic interaction as music then leads us to believe that self, society, and interaction arise as responses to the search for melody, rhythm, and harmony and the rejection of un-esthetic noises, monotality, and endless silence. Viewing meaning, 
self, and society as music highlights the existential and somatic dimensions of music's expressive language. Basic bodily states such as calm, excitation, tension, relaxation, exaltation, and despair find expression in the musical properties of existence as sonorous esthetic experiences such as repetition, diversity, evolution, and periodicity. "The transposition of these rhythms, tendencies, and modalities of movement into the sound-structure of music constitutes music's basic expressive language" (Francès cited in Nattiez 1990:119), as well as esthetic and embodied meaning's potential for all of symbolic interaction. In Dewey's words,

Music having sound as its medium thus necessarily expresses in a concentrated way the shocks and instabilities, the conflicts and resolutions, that are the dramatic changes enacting upon the more enduring background of nature and human life. The tension and the struggle has its gatherings of energy, its discharges, its attacks and defenses, its mighty warrings and its peaceful meetings, its resistances and resolutions, and out of these things music weaves its web. [Music] expresses stir, agitation, movement, the particulars and contingencies of existences-which, nevertheless, are as ingrained in nature and as typical in experience as are its structural permanences. With only a background there would be monotony and death; with only change and movement there would be chaos, not even recognized as disturbed or disturbing. ([1934] 1959:236)

Herein, then, lie the core, feasibility, and usefulness of viewing symbolic interaction as music. Within this musical metaphor, meaning, self, and society become the emerging product of a complex process of poietics and esthetics and, furthermore, a goal striven toward by social agents struggling to create and perceive esthetic value as an existential objective. In this sense, symbolic interaction becomes the concerted action of individuals and semiotic traces, organized by the conflicting versions of forms, tone colors, rhythms, melodies, and harmonies within self and society.

Acknowledgments: The authors are indebted to Joe Kotarba and Eugene Halton for their encouragement and review of this work.

\section{NOTE}

1. Similar to Dilthey (1927), Weber (1958) also found music to be distinct from and therefore irreducible to language. Weber began to develop an analysis of the social correlates of the sound structures of music that was similar to the sociolinguistic study of the morphemic structure of language (see Honigsheim 1989). A similar argument is also made by Simmel ([1882] 1968), who believed that music expressed the strength of human excitement better than words ever could.

\section{REFERENCES}

Becker, Howard S. 1982. Art Worlds. Berkeley: University of California Press.

Blumer, Herbert. 1969. Symbolic Interactionism: Perspective and Method. Berkeley: University of California Press. 
Bourdieu, Pierre. 1984. Distinction: A Social Critique of the Judgment of Taste. Cambridge, MA: Harvard University Press.

Brown, Richard Harvey. 1977. A Poetic for Sociology: Toward a Logic of Discovery for the Human Sciences. Cambridge: Cambridge University Press.

Chandler, Daniel. 2002. Semiotics for Beginners. New York: Routledge. Retrieved January 2, 2005, from http://www.aber.ac.uk/media/Documents/S4B/semiotic.html.

Csikszentmihalyi, Mihaly and Eugene Halton. 1981. The Meaning of Things: Domestic Symbols and the Self. Cambridge: Cambridge University Press.

DeNora, Tia. 2000. Music in Everyday Life. Cambridge: Cambridge University Press.

Dewey, John. 1925. Experience and Nature. Chicago: Open Court. . [1934] 1959. Art as Experience. New York: Capricorn.

Dilthey, Willhelm. 1927. Der Aufbau der Geschichtlichen Welt in den Geisteswissenschaften. Leipzig: Vandenhoeck \& Ruprecht.

Fine, Gary Alan. 1996. Kitchens: The Culture of Restaurant Work. Berkeley: University of California Press.

Francés, Robert. 1958. La perception de la musique. Paris: PUF.

Gilson, Etienne. 1963. Introduction aux arts du beaux. Paris: Vrin.

Goffman, Erving. 1959. The Presentation of Self in Everyday Life. New York: Anchor Books.

Granger, Gilles-Gaston. 1968. Essai d'une Philosophie du Style. Paris: Colin.

Grossberg, Lawrence. 1993. "Is Anybody Listening? Does Anybody Care? 'On the State of Rock." Pp. 41-58 in Microphone Friends: Youth Music and Youth Culture, edited by A. Ross and T. Rose. London: Routledge.

Halton, Eugene. 1986. Meaning and Modernity: Social Theory in the Pragmatic Attitude. Chicago: University of Chicago Press.

Holstein, James and Jaber Gubrium. 2000. The Self We Live By: Narrative Identity in a Postmodern World. New York: Oxford University Press.

Honigsheim, Paul. 1989. Sociologists and Music: An Introduction to the Study of Music and Society, 2nd ed., edited by P. Etzkorn. New Brunswick and London: Transaction.

Lakoff, George and Mark Johnson. 1980. Metaphors We Live By. Chicago: University of Chicago Press.

Mead, George Herbert. 1926. “The Nature of Esthetic Experience.” International Journal of Ethics 36:382-92. 1938. The Philosophy of the Act. Chicago: University of Chicago Press.

Nattiez, Jean-Jacques. 1990. Music and Discourse: Toward a Semiology of Music, translated by C. Abbate. Princeton, NJ: Princeton University Press.

Nisbet, Robert. 1976. Sociology as an Art Form. New York: Oxford University Press.

Peirce, Charles Sanders. 1931. The Collected Papers of Charles Sanders Peirce. Cambridge, MA: Harvard University Press.

Sacks, Oliver. 1990. Awakenings. London: Picador.

Sheperd, John and Peter Wicke. 1997. Music and Cultural Theory. New York: Polity Press.

Shusterman, Richard. 1992. Pragmatist Esthetics: Living Beauty, Rethinking Art. Oxford: Blackwell.

Simmel, Georg. [1882] 1968. "Psychological and Ethnological Studies on Music." Pp. 98-140 in The Conflict in Modern Culture, and Other Essays, translated by P. Etzkorn. New York: Teachers College Press.

Washabaugh, William. 1996. Flamenco: Passion, Politics, and Popular Culture. Oxford: Berg.

Willis, Paul. 1978. Profane Culture. London: Routledge.

Weber, Max. 1958. The Rational and Social Foundations of Music. Carbondale: Southern Illinois University Press. 